\title{
Development of the Endothelium: An Emphasis on Heterogeneity
}

\author{
Laura A. Dyer, Ph.D. ${ }^{1}$ and Cam Patterson, M.D., M.B.A. ${ }^{1}$ \\ ${ }^{1}$ McAllister Heart Institute, University of North Carolina, Chapel Hill, North Carolina.
}

\begin{abstract}
The endothelium is composed of specialized epithelial cells that line the vasculature, the lymph vessels, and the heart. These endothelial cells are characterized by their stratification and are connected via intercellular junctions that confer specific permeability. Although all endothelium acts as a barrier, considerable heterogeneity exists among different organs and even within vessels. During development, the endothelial cells are specified before they migrate to their final destination, and then they commit to an arterial or venous fate. From the venous endothelial cell population, a subset of cells is further specified as lymphatic endothelium. The endothelium can be highly permeable, as in the lymph vessels, or impenetrable, as in the blood-brain barrier. These differences arise during development and are orchestrated through a series of signaling pathways. This review details how endothelial cells arise and are directed to their specific fate, specifically targeting what differentiates endothelial populations.
\end{abstract}

\section{Keywords}

Hemangioblast; arterial; venous; lymphatic; endothelium

\section{THE ORIGIN OF ENDOTHELIAL CELLS}

During the early stages of development, the embryo and extraembryonic tissue consist of two cell layers: the epiblast and the hypoblast. The epiblast expresses bone morphogenic protein (BMP) 4, which is downregulated when the primitive streak forms and the epiblast ingresses to form the mesoderm (Fig. 1A). ${ }^{1}$ Although BMP4 is sufficient to induce mesodermal differentiation in embryonic stem cells, 2,3 epiblast-derived basic fibroblast growth factor (bFGF) and hypoblast-derived activin induce mesoderm formation in the embryo. ${ }^{4-6}$ Interestingly, the hypoblast can be removed before gastrulation and endothelial precursor blood islands still form, ${ }^{7}$ indicating that bFGF is sufficient for mesoderm induction. As the mesoderm ingresses, the epiblast re-expresses BMP4 in the non-neural ectoderm. ${ }^{8}$ This BMP signal is necessary for patterning the mesoderm and setting aside a ventral mesodermal population that can give rise to the endothelium. ${ }^{4,9}$

From the mesoderm, bFGF and activin A induce specification of the hemangioblast, the common precursor of endothelial and hematopoietic cells (Fig. 1B). This induction is observed within 3 hours of mesodermal exposure to bFGF and activin, ${ }^{3}$ and a capillary plexus can form within 7 hours. ${ }^{10}$ BMP4 can also induce the expression of a hallmark endothelial cell marker, receptor tyrosine kinase Flk1 (fetal liver kinase 1), ${ }^{2,3}$ suggesting

Copyright () 2010 by Thieme Medical Publishers, Inc., 333 Seventh Avenue, New York, NY 10001, USA. Tel: +1(212) 584-4662.

Address for correspondence and reprint requests: Cam Patterson, M.D., McAllister Heart Institute, University of North Carolina, Chapel Hill, NC 27599-7525 (cpatters@med.unc.edu). 
that the results observed with bFGF and activin may be caused by the induction of mesoderm rather than the specification of the hemangioblast. In addition to Flk1, stem cell leukemia (SCL) and the adherens junction protein vascular endothelial (VE)-cadherin also mark these endothelial precursors. ${ }^{11,12}$ Flk1/SCL-positive hemangioblasts within the mesoderm swell to form blood island clusters (Fig. 1C). ${ }^{13,14}$ These Flk1/SCL-positive clusters are induced by vascular endothelial growth factor (VEGF)-A and Indian hedgehog signals from the extraembryonic endoderm ${ }^{15-19}$ and express transcription factor GATA-1. ${ }^{14}$ These clusters aggregate between the ectoderm (the former epiblast) and the endoderm, which also forms during gastrulation. ${ }^{20}$ These blood island clusters will form both endothelial and hematopoietic cells.

Additional transcription factors can induce Flk1. Cloche is expressed in the zebrafish hemangioblast and is upstream of the homeobox gene hhex and SCL, and hhex can induce both Flk1 and another endothelial marker, Fli1; in chick, hhex is also expressed in blood islands. ${ }^{21,22}$ In the zebrafish, the Ets transcription factor etsrp is restricted to endothelial precursors and differentiated endothelial cells. ${ }^{23}$ Etsrp mRNA can rescue the cloche mutant zebrafish, and SCL expression is reduced in a subset of endothelial precursors in etsrp morphant zebrafish, ${ }^{23}$ indicating that estrp falls between cloche and SCL in the pathway from mesodermal precursor to hemangioblast. Although these upstream transcription factors are important for inducing Flk1, Flk1-null mice lack blood islands and vessels and die between E8.5 and E9.5, highlighting the importance of this specific gene for vasculogenesis. ${ }^{15}$

The cells in these blood islands undergo one of two transitions: The outer cells flatten and become endothelium while the inner cells differentiate as hematopoietic cells. ${ }^{13}$ The endothelial cells can now be identified by their expression of VE-cadherin, receptor tyrosine kinase Tie2, and PECAM (platelet endothelial cell adhesion molecule, also known as CD31). Although no markers yet distinguish different subsets of endothelial cells at this stage, cell-tracing experiments have shown that each endothelial cell will contribute only to arteries or veins. ${ }^{24}$ However, further differentiation is required before the endothelial cells are fully committed to their particular fate.

\section{DIFFERENTIATION INTO HETEROGENEOUS POPULATIONS}

Once specified, endothelial cells from the blood islands coalesce to form interconnected tubes that create a capillary plexus. Interestingly, endothelial cells express PlexinD1, which sets up migratory patterns and provides guidance cues. ${ }^{25}$ One of its ligands, Semaphorin3A, is present in the somites of zebrafish, and PlexinD1 specifically guides the intersomitic vessels in zebrafish, with no effect on specification or differentiation. ${ }^{25}$ After the heart begins contracting, the vascular plexus undergoes dramatic remodeling, and the endothelial tubes are exposed to environmental cues that influence their differentiation. The apical side of the endothelial cells senses mechanical forces such as transmural pressure, shear stress, and pulsatile flow, and the basolateral side senses mechanical forces through integrin receptors. ${ }^{26}$ Shear stress can induce PECAM in embryoid bodies. ${ }^{27}$ Healthy shear stress can induce transcription factors like Kruppel-like factor-2, which regulates peripheral vascular resistance. ${ }^{28,29}$ In addition, laminar shear stress, which is present in straight arterial vessels, induces VE-cadherin; the strongly expressing VE-cadherin-positive endothelial cells elongate compared with their cuboidal counterparts in more torturous venous vessels, which are exposed to slower flow rates and less shear stress. ${ }^{30}$ In addition, laminar shear stress also induces gap junction proteins connexins 37 and 40, which maintain intercellular communication, and organizes F-actin, which is essential for a functional endothelial barrier. ${ }^{29}$ The tight junction protein occludin is also induced by shear stress, and it inhibits 
permeability. ${ }^{31}$ These biochemical and biomechanical forces trigger distinct signaling pathways, including those pathways initiated by PECAM, VE-cadherin, and VEGF-R. ${ }^{30}$

In addition to environmental cues, endothelial cells are also exposed to signaling pathways that affect their differentiation. A striking example of how a signaling pathway can affect both arterial and venous differentiation is observed in the dorsal aorta and cardinal vein. The endothelial cells that will comprise the dorsal aorta are close to the notochord, a Sonic hedgehog source. ${ }^{32}$ Sonic hedgehog induces high levels of VEGF in the somites, which in turn induces Notch in the adjacent dorsal aorta, and Notch is upstream of arterial marker ephrin B2, Notch receptor delta-like protein 4, neuropilin-1, and phosphorylated Erk. ${ }^{32,33}$ Transcription factors Foxc1 and Foxc2 also induce neuropilin-1, which is a VEGF coreceptor, and Notch, eph, PE-CAM, Flk, Tie2, and delta-like protein $4 .{ }^{34,35}$ In addition, Sonic hedgehog also inhibits the lymphatic endothelial marker and Tie2 ligand angiopoietin-2, thus reinforcing the arterial fate of the endothelial cells closest to the notochord. ${ }^{36}$

To achieve a venous fate, presumably lower Sonic hedgehog levels act on the cardinal vein to induce low levels of VEGF, which induces chicken ovalbumin upstream promoter transcription factor II (COUP-TFII). COUP-TFII inhibits Notch signaling and thus blocks arterial differentiation. ${ }^{37,38}$ The Hox genes also program venous fate; HoxA13 co-localizes with PECAM and induces FoxF1 and Tie2, which is initially expressed in all endothelial cells but eventually restricts to the venous lineage. ${ }^{39}$ Furthermore, venous endothelium expresses the ephrin receptor ephB4 (rtk5 in zebrafish), ${ }^{40}$ which allows signaling between the arterial and venous endothelium and may be responsible for segregating arterial and venous endothelium. ${ }^{41}$

The venous endothelium gives rise to the lymphatic endothelium. In mouse, a subset of the venous endothelial cells express Sox 18 at E9.5, ${ }^{42}$ which subsequently induces Prox 1 , the master regulator of lymphatic vascular development, by E10.5. ${ }^{43-45}$ Prox 1-positive cells bud off the cardinal vein and move dorsoanteriorly to form the lymphatic network. ${ }^{43}$ Prox 1 upregulates FGF receptor $3,{ }^{46}$ which is the main receptor for FGF-2 (bFGF) and promotes proliferation. FGF-2 induces VEGF-C, ${ }^{47}$ whose main receptor, VEGFR3, is restricted to lymphatic endothelial cells. ${ }^{48}$ Another factor, collagen and calcium-binding EGF domain 1 (CCBE1), is required in the adjacent mesenchyme during lymphatic sprouting and is thought to provide migratory cues, as the CCBE1-null zebrafish (full of fluid) lacks budding lymphatic vessels. ${ }^{49}$ In addition to these positive regulators, HoxA13, which promotes the venous endothelial fate, must be turned off to allow lye-1 (lymphatic endothelial gene) to be expressed. ${ }^{39}$ Because the lymphatic endothelium is not under the influence of Sonic hedgehog, it expresses angiopoietin- $2,{ }^{39}$ which destabilizes the adhesion of mural cells to the endothelium and is required for lymphatic activity. ${ }^{50}$ An additional factor that is essential for lymphatic development is the transmembrane protein podoplanin, ${ }^{51}$ an adhesive protein that binds to the secreted protein galectin- $8 .{ }^{52}$ Because galetcin- 8 binds extracellular matrix proteins such as integrins, ${ }^{53}$ podoplanin and galetcin- 8 may be required to anchor the lymphatic endothelial cells once they have completed their migration.

\section{VASCULAR ENDOTHELIUM CHARACTERISTICS}

The vascular endothelium consists of a single layer of cells that line the luminal surface of the vascular system and regulate the transport of macromolecules and blood components from the interstitium to the lumen of the vessel. The vascular endothelium is divided into arterial and venous endothelia, with additional differences between larger and smaller vessels. These specific vascular regions have distinctive differences that support their varied 
roles, ranging from changes in the vessels themselves to differences in the surrounding milieu.

\section{Morphological Differences}

As the primitive vascular plexus begins to remodel, the first observable differences are between arterial and venous vessels. The arterial vessels undergo more retraction to yield vessels with few branches and a large surrounding avascular area, ${ }^{54}$ whereas the veins are more irregular in shape, with more branches (Fig. 2). Proliferation is also higher in venous endothelial cells, which may further contribute to these morphological differences. ${ }^{55}$

\section{Endothelial Support Differences}

Arteries are surrounded by vascular smooth muscle cells. The endothelium secretes extracellular matrix proteins, so the smooth muscle cells have no direct contact with the endothelial cells (Fig. 2). The vascular smooth muscle provides mechanical support and elasticity, mediated by contractile proteins such as smoothelin-B. ${ }^{56}$ These vascular smooth muscle cells migrate toward the larger primary arteries and subsequently cover the branches ${ }^{54}$ Because the arterial endothelial cells are under such high shear stress, it is unsurprising that they would need this additional support. In contrast, venous endothelial cells have few supporting vascular smooth muscle cells, have thinner walls, and experience less shear stress.

Interestingly, some arterial endothelial cells, such as the coronary arteries, are atherosusceptible, whereas other arterial endothelial cells, such as the iliac arteries, are atheroresistant. ${ }^{57}$ The coronary arteries preferentially express atherosclerosis-related genes, such as transcription factor early growth factor-1, proinflammatory transcription factor c-FOS, and genes that are related to inflammation, oxidation, and lipid metabolism. ${ }^{57}$ Iliac arteries, in contrast, express genes that mediate vascular remodeling and angiogenesis as well as cytoprotective genes. ${ }^{57}$ Although the cause of these differences is currently unknown, Zhang et al hypothesize that the changes may be caused by the local mechanical environment, such as differences in shear stress and circumferential strain. ${ }^{57}$

\section{Endothelial Plasticity}

Despite evidence that arterial/venous fate is determined before endothelial tubes form, this distinction is plastic. In chick, the early endothelial cells have an anterior/venous and posterior/arterial association. However, as the vitelline artery forms, formerly arteryassociated endothelial cells in the posterior capillaries receive less blood flow, retract from the artery, and become incorporated into the vitelline veins. ${ }^{58}$ Quail-chick chimeras that have transplanted arterial and venous vessel grafts showed that these endothelial cells can change identity, incorporate into the other vessel, and switch the gene expression profile to match the host vessel. ${ }^{59,60}$

\section{Large Vessel versus Microvessel Endothelial Cells}

Because large vessels (arteries and veins) primarily serve to transport blood, whereas the smaller arterioles regulate vascular tone and venules are the primary site of permeability during inflammation, ${ }^{61}$ it is unsurprising that large and small vessels express different sets of genes. Through microarray analysis of a series of endothelial cell lines, Chi and colleagues characterized the hallmark genes of endothelial cells from large and small arteries and veins. ${ }^{62}$ Large vessel endothelial cells are surrounded by a thick vascular wall and express a set of genes involved in the biosynthesis and remodeling of the extracellular matrix. In addition to extracellular matrix proteins, they also express cell-cell adhesion proteins such as N-cadherin and activated leukocyte cell adhesion molecule, which help 
support barrier function. ${ }^{63}$ They also express several genes associated with neuronal migration, which suggests that these endothelial cells can respond to the same cues that guide neuronal migration. ${ }^{62}$

Microvessel endothelial cells, in contrast, express genes that encode basement membrane proteins and are also tightly associated with the basement membrane. ${ }^{62}$ Although both macro- and microvessels have the same level of actin, the actin filaments are more stable in microvessels. ${ }^{63}$ In addition, they express genes that traffic circulating blood cells and pathogens as well as genes that support lipid transport and metabolism. ${ }^{62}$

\section{Lymphatic Endothelial Characteristics}

The lymphatic endothelium is composed of a single layer of endothelial cells that line the lymph vessels and is more permeable than the vascular endothelium (Fig. 2). Its main functions are to remove plasma proteins that have filtered through the capillaries into the tissue spaces, transport immune cells, and take up dietary fat. These processes occur, not through tight or adherens junctions, but through overlapping button-like intercellular junctions that open and close in response to interstitial pressure. ${ }^{64,65}$ In addition, the major lymphatic vessels are surrounded by smooth muscle cells that generate the pulsatile force needed to move lymph. ${ }^{66}$

\section{SPECIALIZED ENDOTHELIUM}

\section{Endocardium}

Although the endocardium consists of endothelial cells that line the heart, it is distinct from the endothelium. Like the endothelium, it expresses Flk1, VE-cadherin, and Tie2 during development ${ }^{67}$ However, its origin is controversial; studies in zebrafish indicate that it shares its origin with the hemangioblast, whereas labeling studies in chick indicate that the myocardium and endocardium are distinguished in the primitive streak. ${ }^{68}$ However, lineagemarking studies in mouse have indicated that the mesoderm gives rise to both myocardium and endocardium. ${ }^{69,70}$ Misfeldt and colleagues recently confirmed that the endocardium shares its origin with the myocardium as opposed to the endothelium, but these studies were performed in embryoid bodies and lack the spatiotemporal constraints of the embryo. ${ }^{71}$ Thus it is unclear how to resolve the single-cell chick tracings with the lineage-marking mouse studies. Regardless of origin, the endocardium serves a major role in forming the cushions that will eventually remodel to form the valve leaflets ${ }^{72}$ and also in inducing trabeculation. ${ }^{73}$

\section{Fenestrated Endothelium}

Fenestrated endothelium is characterized by the presence of circular windows (or fenêtres) in the cell body. These fenestrations allow transport of water and small hydrophilic molecules, and fenestrated endothelium is present in organs that resorb water and small molecules or hormones, such as the kidney and liver. ${ }^{74,75}$

\section{Blood-Brain Barrier}

The blood-brain barrier is unique in that it is a non-fenestrated endothelium. Specific tight junctions result in impermeable connections between endothelial cells, separating the cerebral capillaries and the brain. These tight junctions allow the selective transport of nutrients and consist of claudin 3 and occludins. ${ }^{76}$ If blood-brain barrier endothelial cells are placed in culture, they rapidly lose their impermeability, indicating that they receive a constant supply of inductive factors, which may include bFGF, angiopoietin-1, and transforming growth factor $\beta .{ }^{77,78}$ In addition to transport through the tight junctions, small gaseous molecules and lipophilic agents can diffuse through the endothelium. ${ }^{78}$ 


\section{ENDOTHELIAL DYSFUNCTION}

\section{Arterial Dysfunction}

The arterial endothelium releases nitric oxide, endothelin, and prostacyclin, which regulate vascular tone, platelet activity, and blood coagulation. Any event that disrupts endothelial integrity thus disrupts these processes as well. Coronary artery disease is one example of a disease that targets the arterial endothelium. Some risk factors cannot be changed, such as age and male gender, but other risk factors can be treated, such as hyper-cholesterolemia. In response to these risk factors, the endothelium increases the expression of adhesion molecules, which leads to intimal thickening and plaque formation. ${ }^{79}$ In addition, hypertension and aging also decrease gap junction expression, thereby decreasing cell-cell communication. ${ }^{80}$

\section{Venous Dysfunction}

The venous circulation returns blood to the heart, which facilitates cardiovascular homeostasis. Chronic venous disease is characterized by obstructed and/or incompetent venous flow and varies based on clinical, etiological, anatomical, and pathophysiology signs and symptoms. ${ }^{81}$ Although disease severity may vary, most cases are caused by vascular hypertension, which results in reflux in the superficial and/or deep venous system and higher-than-normal venous pressures. ${ }^{81}$ Incompetent venous flow is caused by changes in the vessel wall, such as decreased smooth muscle and elastin and increased collagen; these changes result in a weakened, dilated vessel wall. ${ }^{82}$ In addition, high shear stress activates leukocytes, thus activating the inflammatory response pathway. ${ }^{81}$

\section{Lymphatic Dysfunction}

Impaired lymphatic function results in overall swelling, known as lymphedema. This dysfunction can be caused either by decreased transport of lymph through the lymphatic network, as is observed in parasitic infections, ${ }^{83}$ by increased fluid, ${ }^{84}$ or by having fewer capillaries, which is seen in primary congenital lymphedema. Mutations in VEGFR3, FoxC2, and Sox 18 have all been linked to lymphedema. ${ }^{85}$

\section{Blood-Brain Barrier Dysfunction}

Epidemiology studies have linked vascular defects in the blood-brain barrier with Alzheimer's disease ${ }^{86}$ In patients with Alzheimer's disease, the basement membrane is thickened and vacuous, and the microvessels thin and exhibit increased tortuosity compared with control subjects. ${ }^{87}$ The vascular changes are due to both amyloid $\beta$-induced vascular dysfunction and reduced neuronal processing, and the degree of microvessel degeneration is related to amyloid plaque formation. ${ }^{88,89}$ One potential connection between the vascular and neuronal biology is apolipoprotein $\mathrm{E}$, which is involved in both atherosclerosis and mobilizing cholesterol in the brain after ischemia. ${ }^{90}$ In addition, apolipoprotein $\mathrm{E}$ may destabilize the supporting smooth muscle cells and disrupt tight junctions. ${ }^{89}$

\section{CONCLUSIONS}

The endothelial cell may have humble origins during gastrulation, but the endothelium is an essential component of all organs. Understanding how a basic endothelial cell can differentiate into such specialized cells is essential for appreciating the complexity of endothelial disorders and providing better treatments. Different organs have different plumbing requirements, as it were, that are met by these heterogeneous endothelial populations. By appreciating the different functions and machinery that these populations possess, it should be easier to harness the cells' plasticity, resulting in more effective vessel grafts and the ability to reprogram endothelial cells that have become dysfunctional. 


\section{Acknowledgments}

We would like to thank the National Institutes of Health for funding support (\#2R01HL061656-11).

\section{REFERENCES}

1. Streit A, Lee KJ, Woo I, Roberts C, Jessell TM, Stern CD. Chordin regulates primitive streak development and the stability of induced neural cells, but is not sufficient for neural induction in the chick embryo. Development. 1998; 125(3):507-519. [PubMed: 9425145]

2. Park C, Afrikanova I, Chung YS, et al. A hierarchical order of factors in the generation of FLK1and SCL-expressing hematopoietic and endothelial progenitors from embryonic stem cells. Development. 2004; 131(11):2749-2762. [PubMed: 15148304]

3. Pearson S, Sroczynska P, Lacaud G, Kouskoff V. The stepwise specification of embryonic stem cells to hematopoietic fate is driven by sequential exposure to Bmp4, activin A, bFGF and VEGF. Development. 2008; 135(8):1525-1535. [PubMed: 18339678]

4. Huber TL, Zhou Y, Mead PE, Zon LI. Cooperative effects of growth factors involved in the induction of hematopoietic mesoderm. Blood. 1998; 92(11):4128-4137. [PubMed: 9834218]

5. Karabagli H, Karabagli P, Ladher RK, Schoenwolf GC. Comparison of the expression patterns of several fibroblast growth factors during chick gastrulation and neurulation. Anat Embryol (Berl). 2002; 205(5-6):365-370. [PubMed: 12382140]

6. Mitrani E, Ziv T, Thomsen G, Shimoni Y, Melton DA, Bril A. Activin can induce the formation of axial structures and is expressed in the hypoblast of the chick. Cell. 1990; 63(3):495-501. [PubMed: 2225063]

7. Azar Y, Eyal-Giladi H. Marginal zone cells-the primitive streak-inducing component of the primary hypoblast in the chick. J Embryol Exp Morphol. 1979; 52:79-88. [PubMed: 521755]

8. Chapman SC, Schubert FR, Schoenwolf GC, Lumsden A. Analysis of spatial and temporal gene expression patterns in blastula and gastrula stage chick embryos. Dev Biol. 2002; 245(1):187-199. [PubMed: 11969265]

9. Marom K, Levy V, Pillemer G, Fainsod A. Temporal analysis of the early BMP functions identifies distinct anti-organizer and mesoderm patterning phases. Dev Biol. 2005; 282(2):442-454. [PubMed: 15950609]

10. Flamme I, Risau W. Induction of vasculogenesis and hematopoiesis in vitro. Development. 1992; 116(2):435-439. [PubMed: 1286617]

11. Nishikawa SI, Nishikawa S, Hirashima M, Matsuyoshi N, Kodama H. Progressive lineage analysis by cell sorting and culture identifies FLK1 + VE-cadherin + cells at a diverging point of endothelial and hemopoietic lineages. Development. 1998; 125(9):1747-1757. [PubMed: 9521912]

12. Faloon $\mathrm{P}$, Arentson E, Kazarov A, et al. Basic fibroblast growth factor positively regulates hematopoietic development. Development. 2000; 127(9):1931-1941. [PubMed: 10751181]

13. Kessel J, Fabian BC. Graded morphogenetic patterns during the development of the extraembryonic blood system and coelom of the chick blastoderm: a scanning electron microscope and light microscope study. Am J Anat. 1985; 173:99-112. [PubMed: 20726115]

14. Minko K, Bollerot K, Drevon C, Hallais MF, Jaffredo T. From mesoderm to blood islands: patterns of key molecules during yolk sac erythropoiesis. Gene Expr Patterns. 2003; 3(3):261-272. [PubMed: 12799070]

15. Shalaby F, Rossant J, Yamaguchi TP, et al. Failure of blood-island formation and vasculogenesis in Flk-1-deficient mice. Nature. 1995; 376(6535):62-66. [PubMed: 7596435]

16. Ferrara N, Heinsohn H, Walder CE, Bunting S, Thomas GR. The regulation of blood vessel growth by vascular endothelial growth factor. Ann N Y Acad Sci. 1995; 752:246-256. [PubMed: 7538737]

17. Belaoussoff M, Farrington SM, Baron MH. Hematopoietic induction and respecification of A-P identity by visceral endoderm signaling in the mouse embryo. Development. 1998; 125(24):5009_ 5018. [PubMed: 9811585] 
18. Baron MH. Molecular regulation of embryonic hematopoiesis and vascular development: a novel pathway. J Hematother Stem Cell Res. 2001; 10(5):587-594. [PubMed: 11672504]

19. Dyer MA, Farrington SM, Mohn D, Munday JR, Baron MH. Indian hedgehog activates hematopoiesis and vasculogenesis and can respecify prospective neurectodermal cell fate in the mouse embryo. Development. 2001; 128(10):1717-1730. [PubMed: 11311154]

20. Gonzalez-Crussi F. Vasculogenesis in the chick embryo. An ultrastructural study. Am J Anat. 1971; 130(4):441-460. [PubMed: 4931925]

21. Liao W, Ho CY, Yan YL, Postlethwait J, Stainier DY. Hhex and scl function in parallel to regulate early endothelial and blood differentiation in zebrafish. Development. 2000; 127(20):4303-4313. [PubMed: 11003831]

22. Crompton MR, Bartlett TJ, MacGregor AD, et al. Identification of a novel vertebrate homeobox gene expressed in haematopoietic cells. Nucleic Acids Res. 1992; 20(21):5661-5667. [PubMed: 1360645]

23. Sumanas S, Lin S. Ets1-related protein is a key regulator of vasculogenesis in zebrafish. PLoS Biol. 2006; 4(1):e10. [PubMed: 16336046]

24. Zhong TP, Childs S, Leu JP, Fishman MC. Gridlock signalling pathway fashions the first embryonic artery. Nature. 2001; 414(6860):216-220. [PubMed: 11700560]

25. Torres-Vázquez J, Gitler AD, Fraser SD, et al. Van N Pham. Semaphorin-plexin signaling guides patterning of the developing vasculature. Dev Cell. 2004; 7(1):117-123. [PubMed: 15239959]

26. Gebb S, Stevens T. On lung endothelial cell heterogeneity. Microvasc Res. 2004; 68(1):1-12. [PubMed: 15219415]

27. Adamo L, Naveiras O, Wenzel PL, et al. Biomechanical forces promote embryonic haematopoiesis. Nature. 2009; 459(7250):1131-1135. [PubMed: 19440194]

28. Lee JS, Yu Q, Shin JT, et al. Klf2 is an essential regulator of vascular hemodynamic forces in vivo. Dev Cell. 2006; 11(6):845-857. [PubMed: 17141159]

29. Dai G, Kaazempur-Mofrad MR, Natarajan S, et al. Distinct endothelial phenotypes evoked by arterial waveforms derived from atherosclerosis-susceptible and -resistant regions of human vasculature. Proc Natl Acad Sci U S A. 2004; 101(41):14871-14876. [PubMed: 15466704]

30. Garin G, Berk BC. Flow-mediated signaling modulates endothelial cell phenotype. Endothelium. 2006; 13(6):375-384. [PubMed: 17169770]

31. Conklin BS, Vito RP, Chen C. Effect of low shear stress on permeability and occludin expression in porcine artery endothelial cells. World J Surg. 2007; 31(4):733-743. [PubMed: 17372666]

32. Lawson ND, Vogel AM, Weinstein BM. Sonic hedgehog and vascular endothelial growth factor act upstream of the Notch pathway during arterial endothelial differentiation. Dev Cell. 2002; 3(1): 127-136. [PubMed: 12110173]

33. Lanner F, Sohl M, Farnebo F. Functional arterial and venous fate is determined by graded VEGF signaling and notch status during embryonic stem cell differentiation. Arterioscler Thromb Vasc Biol. 2007; 27(3):487-493. [PubMed: 17185616]

34. Seo S, Fujita H, Nakano A, Kang M, Duarte A, Kume T. The forkhead transcription factors, Foxc1 and Foxc2, are required for arterial specification and lymphatic sprouting during vascular development. Dev Biol. 2006; 294(2):458-470. [PubMed: 16678147]

35. Hayashi H, Kume T. Foxc transcription factors directly regulate Dl14 and Hey2 expression by interacting with the VEGF-Notch signaling pathways in endothelial cells. PLoS One. 2008; 3(6):e2401. [PubMed: 18545664]

36. Lee SW, Moskowitz MA, Sims JR. Sonic hedgehog inversely regulates the expression of angiopoietin-1 and angiopoietin-2 in fibroblasts. Int J Mol Med. 2007; 19(3):445-451. [PubMed: 17273793]

37. Krishnan V, Pereira FA, Qiu Y, et al. Mediation of Sonic hedgehog-induced expression of COUPTFII by a protein phosphatase. Science. 1997; 278(5345):1947-1950. [PubMed: 9395397]

38. You LR, Lin FJ, Lee CT, DeMayo FJ, Tsai MJ, Tsai SY. Suppression of Notch signalling by the COUP-TFII transcription factor regulates vein identity. Nature. 2005; 435(7038):98-104. [PubMed: 15875024]

39. Shaut CA, Keene DR, Sorensen LK, Li DY, Stadler HS. HOXA13 Is essential for placental vascular patterning and labyrinth endothelial specification. PLoS Genet. 2008; 4(5) e1000073. 
40. Lawson ND, Scheer N, Pham VN, et al. Notch signaling is required for arterial-venous differentiation during embryonic vascular development. Development. 2001; 128(19):3675-3683. [PubMed: 11585794]

41. Füller T, Korff T, Kilian A, Dandekar G, Augustin HG. Forward EphB4 signaling in endothelial cells controls cellular repulsion and segregation from ephrinB2 positive cells. J Cell Sci. 2003; 116(Pt 12):2461-2470. [PubMed: 12734395]

42. François M, Caprini A, Hosking B, et al. Sox18 induces development of the lymphatic vasculature in mice. Nature. 2008; 456(7222):643-647. [PubMed: 18931657]

43. Wigle JT, Oliver G. Prox 1 function is required for the development of the murine lymphatic system. Cell. 1999; 98(6):769-778. [PubMed: 10499794]

44. Hong YK, Harvey N, Noh YH, et al. Prox1 is a master control gene in the program specifying lymphatic endothelial cell fate. Dev Dyn. 2002; 225(3):351-357. [PubMed: 12412020]

45. Wigle JT, Harvey N, Detmar M, et al. An essential role for Prox 1 in the induction of the lymphatic endothelial cell phenotype. EMBO J. 2002; 21(7):1505-1513. [PubMed: 11927535]

46. Shin D, Anderson DJ. Isolation of arterial-specific genes by subtractive hybridization reveals molecular heterogeneity among arterial endothelial cells. Dev Dyn. 2005; 233(4):1589-1604. [PubMed: 15977181]

47. Kubo H, Cao R, Brakenhielm E, Mäkinen T, Cao Y, Alitalo K. Blockade of vascular endothelial growth factor receptor-3 signaling inhibits fibroblast growth factor-2-induced lymphangiogenesis in mouse cornea. Proc Natl Acad Sci U S A. 2002; 99(13):8868-8873. [PubMed: 12070340]

48. Chang LK, Garcia-Cardeña G, Farnebo F, et al. Dose-dependent response of FGF-2 for lymphangiogenesis. Proc Natl Acad Sci U S A. 2004; 101(32):11658-11663. [PubMed: 15289610]

49. Hogan BM, Bos FL, Bussmann J, et al. Ccbe1 is required for embryonic lymphangiogenesis and venous sprouting. Nat Genet. 2009; 41(4):396-398. [PubMed: 19287381]

50. Maisonpierre PC, Suri C, Jones PF, et al. Angiopoietin-2, a natural antagonist for Tie2 that disrupts in vivo angiogenesis. Science. 1997; 277(5322):55-60. [PubMed: 9204896]

51. Mäkinen T, Norrmén C, Petrova TV. Molecular mechanisms of lymphatic vascular development. Cell Mol Life Sci. 2007; 64(15):1915-1929. [PubMed: 17458498]

52. Cueni LN, Detmar M. Galectin-8 interacts with podoplanin and modulates lymphatic endothelial cell functions. Exp Cell Res. 2009; 315(10):1715-1723. [PubMed: 19268462]

53. Levy Y, Arbel-Goren R, Hadari YR, et al. Galectin-8 functions as a matricellular modulator of cell adhesion. J Biol Chem. 2001; 276(33):31285-31295. [PubMed: 11371555]

54. Benjamin LE, Hemo I, Keshet E. A plasticity window for blood vessel remodelling is defined by pericyte coverage of the preformed endothelial network and is regulated by PDGF-B and VEGF. Development. 1998; 125(9):1591-1598. [PubMed: 9521897]

55. Blose SH, Chacko S. In vitro behavior of guinea pig arterial and venous endothelial cells. Dev Growth Differ. 1975; 17(2):153-165.

56. Rensen SS, Niessen PM, van Deursen JM, et al. Smoothelin-B deficiency results in reduced arterial contractility, hypertension, and cardiac hypertrophy in mice. Circulation. 2008; 118(8):828-836. [PubMed: 18678771]

57. Zhang J, Burridge KA, Friedman MH. In vivo differences between endothelial transcriptional profiles of coronary and iliac arteries revealed by microarray analysis. Am J Physiol Heart Circ Physiol. 2008; 295(4):H1556-H1561. [PubMed: 18689496]

58. le Noble F, Moyon D, Pardanaud L, et al. Flow regulates arterial-venous differentiation in the chick embryo yolk sac. Development. 2004; 131(2):361-375. [PubMed: 14681188]

59. Moyon D, Pardanaud L, Yuan L, Bréant C, Eichmann A. Plasticity of endothelial cells during arterial-venous differentiation in the avian embryo. Development. 2001; 128(17):3359-3370. [PubMed: 11546752]

60. Othman-Hassan K, Patel K, Papoutsi M, Rodriguez-Niedenführ M, Christ B, Wilting J. Arterial identity of endothelial cells is controlled by local cues. Dev Biol. 2001; 237(2):398-409. [PubMed: 11543623]

61. dela Paz NG, D’Amore PA. Arterial versus venous endothelial cells. Cell Tissue Res. 2009; 335(1):5-16. [PubMed: 18972135] 
62. Chi JT, Chang HY, Haraldsen G, et al. Endothelial cell diversity revealed by global expression profiling. Proc Natl Acad Sci U S A. 2003; 100(19):10623-10628. [PubMed: 12963823]

63. Prasain N, Stevens T. The actin cytoskeleton in endothelial cell phenotypes. Microvasc Res. 2009; 77(1):53-63. [PubMed: 19028505]

64. Maby-El Hajjami H, Petrova TV. Developmental and pathological lymphangiogenesis: from models to human disease. Histochem Cell Biol. 2008; 130(6):1063-1078. [PubMed: 18946678]

65. Baluk P, Fuxe J, Hashizume H, et al. Functionally specialized junctions between endothelial cells of lymphatic vessels. J Exp Med. 2007; 204(10):2349-2362. [PubMed: 17846148]

66. Saharinen P, Tammela T, Karkkainen MJ, Alitalo K. Lymphatic vasculature: development, molecular regulation and role in tumor metastasis and inflammation. Trends Immunol. 2004; 25(7):387-395. [PubMed: 15207507]

67. Drake CJ, Fleming PA. Vasculogenesis in the day 6.5 to 9.5 mouse embryo. Blood. 2000; 95(5): 1671-1679. [PubMed: 10688823]

68. Wei Y, Mikawa T. Fate diversity of primitive streak cells during heart field formation in ovo. Dev Dyn. 2000; 219(4):505-513. [PubMed: 11084650]

69. Motoike T, Markham DW, Rossant J, Sato TN. Evidence for novel fate of Flk1 + progenitor: contribution to muscle lineage. Genesis. 2003; 35(3):153-159. [PubMed: 12640619]

70. Saga Y, Kitajima S, Miyagawa-Tomita S. Mesp1 expression is the earliest sign of cardiovascular development. Trends Cardiovasc Med. 2000; 10(8):345-352. [PubMed: 11369261]

71. Misfeldt AM, Boyle SC, Tompkins KL, Bautch VL, Labosky PA, Baldwin HS. Endocardial cells are a distinct endothelial lineage derived from Flk1 + multipo-multipotent cardiovascular progenitors. Dev Biol. 2009; 333(1):78-89. [PubMed: 19576203]

72. Barnett JV, Desgrosellier JS. Early events in valvulogenesis: a signaling perspective. Birth Defects Res C Embryo Today. 2003; 69(1):58-72. [PubMed: 12768658]

73. Meyer D, Birchmeier C. Multiple essential functions of neuregulin in development. Nature. 1995; 378(6555):386-390. [PubMed: 7477375]

74. Ballermann BJ. Glomerular endothelial cell differentiation. Kidney Int. 2005; 67(5):1668-1671. [PubMed: 15840009]

75. Braet F, Wisse E. Structural and functional aspects of liver sinusoidal endothelial cell fenestrae: a review. Comp Hepatol. 2002; 1(1):1. [PubMed: 12437787]

76. Wolburg H, Wolburg-Buchholz K, Kraus J, et al. Localization of claudin-3 in tight junctions of the blood-brain barrier is selectively lost during experimental autoimmune encephalomyelitis and human glioblastoma multiforme. Acta Neuropathol. 2003; 105(6):586-592. [PubMed: 12734665]

77. Liebner S, Corada M, Bangsow T, et al. Wnt/beta-catenin signaling controls development of the blood-brain barrier. J Cell Biol. 2008; 183(3):409-417. [PubMed: 18955553]

78. Abbott NJ, Rönnbäck L, Hansson E. Astrocyte-endothelial interactions at the blood-brain barrier. Nat Rev Neurosci. 2006; 7(1):41-53. [PubMed: 16371949]

79. Tousoulis D, Charakida M, Stefanadis C. Endothelial function and inflammation in coronary artery disease. Post-grad Med J. 2008; 84(993):368-371.

80. Wang HH, Kung CI, Tseng YY, et al. Activation of endothelial cells to pathological status by down-regulation of connexin43. Cardiovasc Res. 2008; 79(3):509-518. [PubMed: 18445604]

81. Bergan JJ, Schmid-Schönbein GW, Smith PD, Nicolaides AN, Boisseau MR, Eklof B. Chronic venous disease. N Engl J Med. 2006; 355(5):488-498. [PubMed: 16885552]

82. Meissner MH, Moneta G, Burnand K, et al. The hemodynamics and diagnosis of venous disease. J Vasc Surg. 2007; 46(suppl S):4S-24S. [PubMed: 18068561]

83. Wynd S, Melrose WD, Durrheim DN, Carron J, Gyapong M. Understanding the community impact of lymphatic filariasis: a review of the sociocultural literature. Bull World Health Organ. 2007; 85(6):493-498. [PubMed: 17639248]

84. Rockson SG. The unique biology of lymphatic edema. Lymphat Res Biol. 2009; 7(2):97-100. [PubMed: 19522679]

85. Jurisic G, Detmar M. Lymphatic endothelium in health and disease. Cell Tissue Res. 2009; 335(1): 97-108. [PubMed: 18648856] 
86. de la Torre JC. Vascular basis of Alzheimer's pathogenesis. Ann N Y Acad Sci. 2002; 977:196215. [PubMed: 12480752]

87. Buée L, Hof PR, Delacourte A. Brain microvascular changes in Alzheimer's disease and other dementias. Ann N Y Acad Sci. 1997; 826:7-24. [PubMed: 9329677]

88. Iadecola C. Neurovascular regulation in the normal brain and in Alzheimer's disease. Nat Rev Neurosci. 2004; 5(5):347-360. [PubMed: 15100718]

89. Jellinger KA. Alzheimer disease and cerebrovascular pathology: an update. J Neural Transm. 2002; 109(5-6):813-836. [PubMed: 12111471]

90. Kalaria RN. The role of cerebral ischemia in Alzheimer's disease. Neurobiol Aging. 2000; 21(2): 321-330. [PubMed: 10867217] 


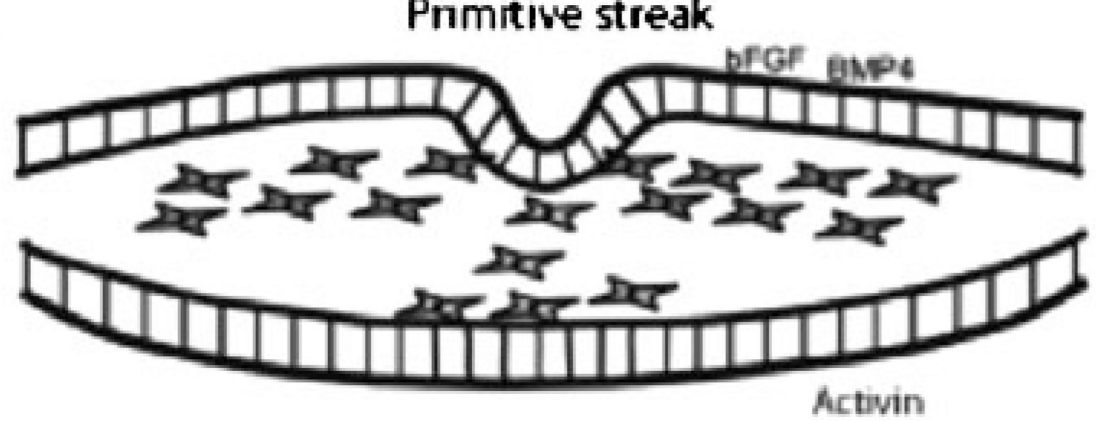

Epiblast

Hypoblast

A 2re ingessing mesoderm

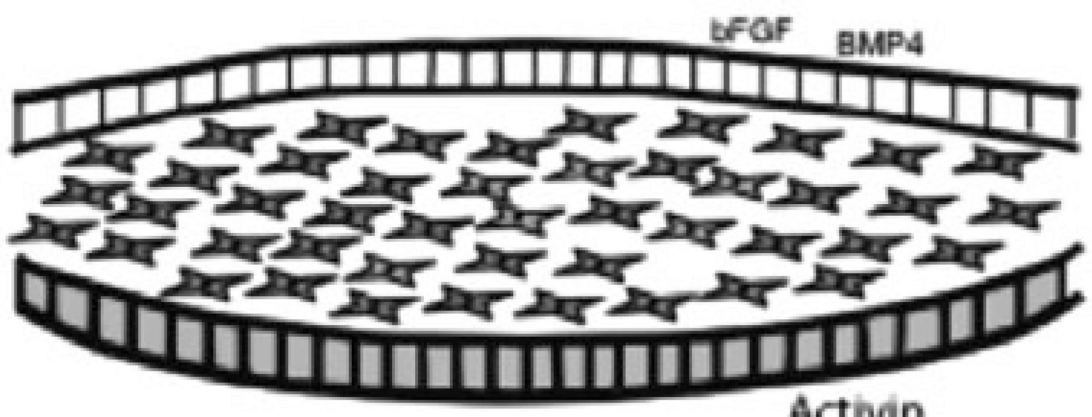

Ecroderm

De $F \mid k 1+, S C L+, L m o 2+$ hemangioblasts
Mes Mesoderm

\section{Activin}

Endoderm

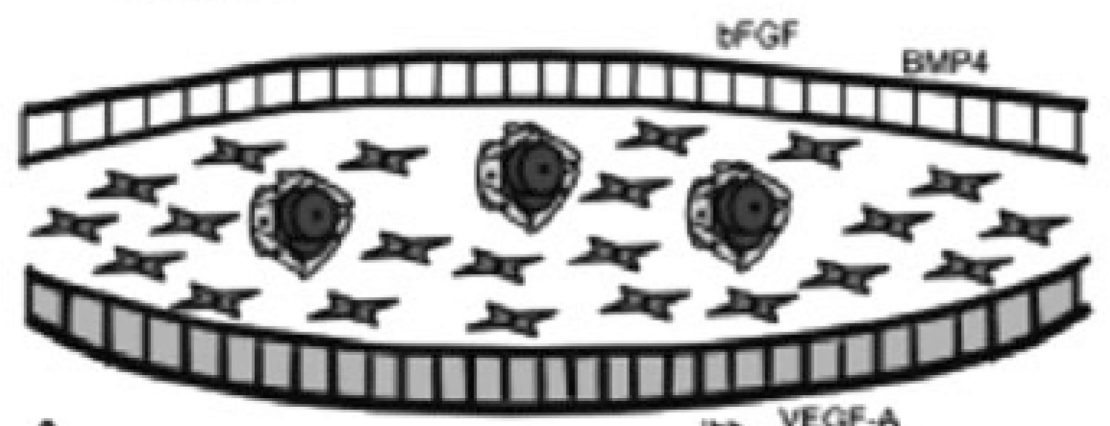

Ectoderm

Flk1 + endothelial cell

$\mathrm{Flk} 1+, \mathrm{SQ}$ + hematopoietic cell

C Der mesoderm

Figure 1.

The endothelium is derived from ingressing mesoderm. (A) Signals from the epiblast and hypoblast induce mesoderm formation. (B) Additional signals from the ectoderm then induce a subset of mesoderm to become hemangioblasts. (C) These hemangioblasts will swell and form clusters. These clusters show the first distinction between the outer endothelial cells and the inner hematopoietic cells. 
Artery
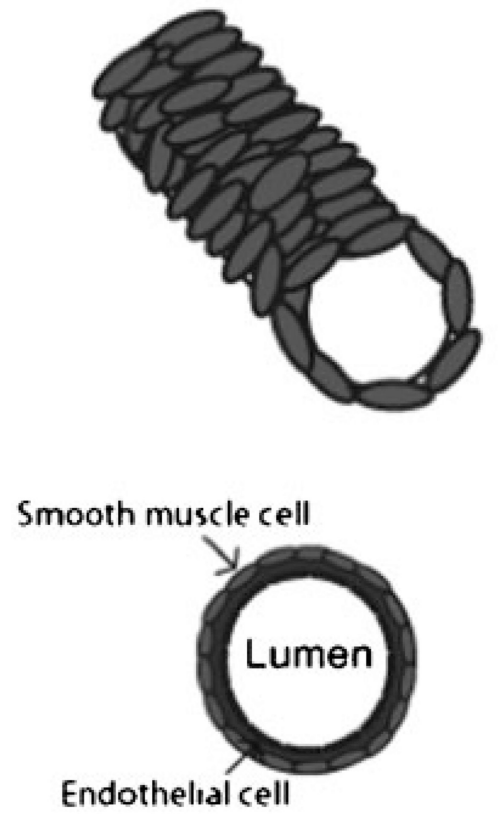

Lumen

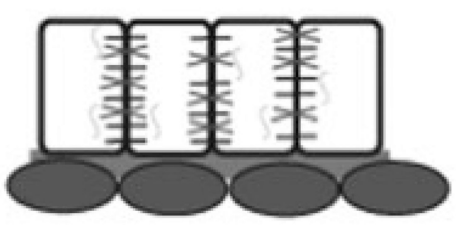

Actin

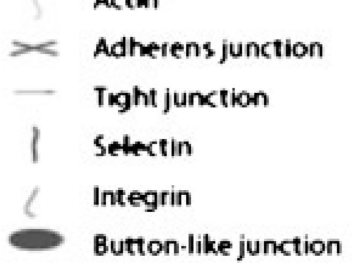

Vein
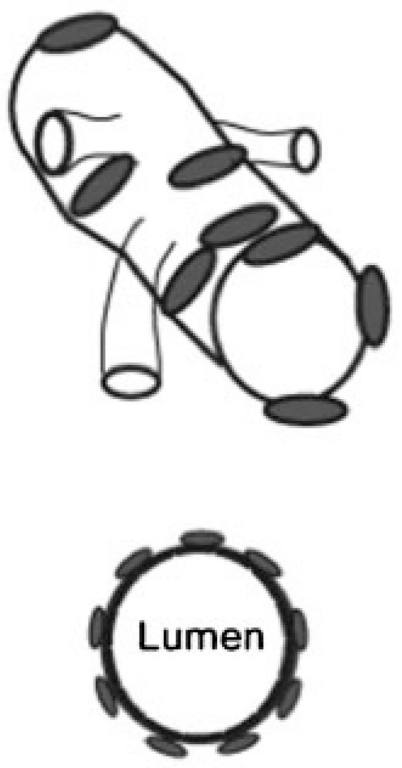

Lumen

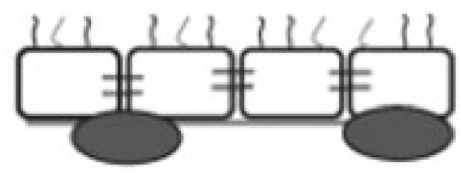

Lymphatic Vessel
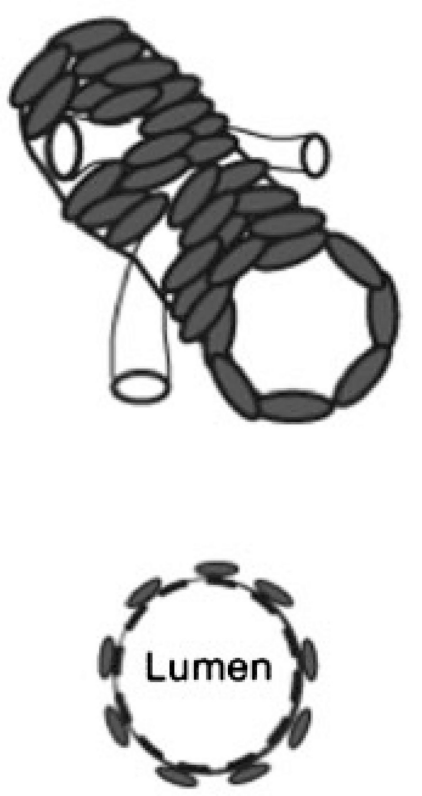

Lumen

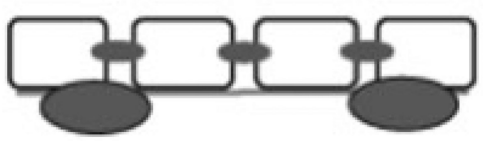

Figure 2.

Arterial, venous, and lymphatic vessels have different characteristics, which stem from the endothelial cell lining. Arterial endothelial cells are tightly connected via tight and adherens junctions, express high levels of actin, deposit a thick layer of extracellular matrix, and are supported by smooth muscle cells. Venous endothelial cells are more permeable with less extracellular matrix, and venous vessels are more flexible than their arterial counterparts. In addition, they display integrins and selectins on their apical surface. Lymphatic endothelial cells are highly permeable, and the major lymphatic vessels are supported by smooth muscle cells; they are connected via large button-like junctions. 